Fisher, C. (1967). In Protein Utilization by Poultry p. 174 [R. A. Morton and E. C. Amoroso, editors]. Fisher, C. \& Morris, T. R. (1967). Br. Poult. Sci. 8, 153.

Hegsted, D. M. (r964). In Mammalian Protein Metabolism Vol. 2, p. I35 [H. N. Munro and J. B. Allison, editors]. New York and London: Academic Press.

Jones, A. S., Hepburn, W. R. \& Boyne, A. W. (196I). F. Sci. Fd Agric. 12, 353.

McWard, G. W., Becker, D. E., Norton, H. W., Terrill, S. W. \& Jensen, A. H. (1959). J. Anim. Sci. I8, 1059 .

Miller, D. S. \& Payne, P. R. (1961). Br. F. Nutr., r5, I1.

Miller, D. S. \& Payne, P. R. (1969). Proc. Nutr. Soc. 28, 225.

Miller, E. L. (1970). FAO Fisheries Repts no. 92.

Morris, T. R. (1968). Br. Poult. Sci., 9, 285.

National Research Council: Committee on Animal Nutrition (1954). Publs natn. Res. Coun., Wash., no. 301.

National Research Council: Committee on Animal Nutrition (1968). Publs natn. Res. Coun., Wash., no. 1599 .

Payne, P. R. (1969). Voeding, 30, 182.

Pfander, W. H. \& Tribble, L. F. (1955). F. Anim. Sci. x4, 545.

United Nations Organization (1968). International Action to Avert the Impending Protein Crisis. New York: United Nations.

Widdowson, E. M. (r962). Proc. Nutr. Soc., 2r, I2x.

\title{
Problems in the determination of the trace element requirements of animals
}

By C. F. Mills and R. B. Williams, Rozett Research Institute, Bucksburn, Aberdeen, $A B 2$ gSB

Statements of the trace element requirements of man and domesticated animals have appeared in publications of the (US) National Research Council (1960, 1964, I966, r968a, $b$, I970), the (UK) Agricultural Research Council (1963, r965, r967) and in authoritative reviews such as those of Underwood (1962, 1966). In presenting these statements the authors repeatedly emphasize the provisional nature of their conclusions, the many factors which limit the value of a single statement of requirement and the scarcity of published information relating physiological performance to trace element intake. This review examines some of the practical problems behind the determination of trace element requirements and considers the value and limitations of statements of requirement under practical and experimental conditions.

Several different approaches have been employed to assess trace element requirements, namely (I) studies of relationships between dietary concentration and physiological response, (2) studies of input/output relationships in balance trials, (3) factorial assessments of requirements based upon body composition studies coupled with estimates of endogenous excretion, (4) estimates derived from the analysis of field data obtained in association with studies of suspected deficiency disorders. Each of these approaches is subject to hazards of execution and interpretation and, undoubtedly, the greatest among these are the the problems caused by adventitious contamination during the conduct of the experiment. 
Probably the most important reason for the absence of satisfactory data on requirements for most of the trace elements is the practical difficulty of experimentation in this field in which the need is to maintain constant and often low intakes of an element which very frequently may be present in abundance in structural materials used for animal housing or in equipment used for the preparation of food or the collection of urine and faeces. Table $\mathrm{r}$ illustrates the nature of trace element

Table $\mathrm{x}$. Trace element content of materials that are frequently used for construction of animal accommodation and for sample collection

\begin{tabular}{|c|c|c|c|}
\hline $\begin{array}{l}\text { Approximate } \\
\text { concentration }(\mu \mathrm{g} / \mathrm{g})\end{array}$ & $\begin{array}{l}\text { High } \\
>500\end{array}$ & $\begin{array}{l}\text { Plastics* } \\
\text { Medium } \\
200-500\end{array}$ & $\begin{array}{l}\text { Low } \\
\text { roo-200 }\end{array}$ \\
\hline $\begin{array}{l}\text { Polyethylene } \\
\text { High density, white } \\
\text { High density, yellow } \\
\text { High pressure, natural }\end{array}$ & $\mathrm{Zn}, \mathrm{Cd}$ & $\mathrm{Fe}$ & $\begin{array}{l}\mathrm{Cr}, \mathrm{Cd} \\
\mathrm{Cr}, \mathrm{Cu}\end{array}$ \\
\hline $\begin{array}{l}\text { Polyvinylchloride: } \\
\text { Sheet, grey } \\
\text { Tube, clear }\end{array}$ & $\begin{array}{c}\mathrm{Zn} \\
\mathrm{Cd}, \mathrm{Cu}\end{array}$ & $\begin{array}{l}\mathrm{Fe} \\
\mathrm{Sn}\end{array}$ & $\mathrm{Cd}$ \\
\hline $\begin{array}{l}\text { Perspex: } \\
\text { Clear } \\
\text { Black }\end{array}$ & $\mathrm{Cr}, \mathrm{Cu}$ & & $\begin{array}{c}\mathrm{Cu} \\
\mathrm{Sn}, \mathrm{Pb}\end{array}$ \\
\hline $\begin{array}{l}\text { Phenolic resin: } \\
\text { Black }\end{array}$ & $\mathrm{Mn}, \mathrm{Zn}$ & $\mathrm{Cr}, \mathrm{Fe}$ & $\mathrm{Cd}$ \\
\hline $\begin{array}{l}\text { Stainless steels } \uparrow \\
\text { Aluminium alloys }\rceil\end{array}$ & \multicolumn{3}{|c|}{$\begin{array}{l}\text { Alloys } \\
\text { Cr to } 20 \% ; \mathrm{Mn} \text { to } 2 \% ; \text { Mo to } 3.5 \% ; \text { Se to } 0.6 \% \text {; } \\
\text { Pb to } 0.34 \% \\
\text { Cu to } 8 \% ; \mathrm{Zn} \text { to } 13 \%\end{array}$} \\
\hline
\end{tabular}

inclusions in plastic materials and in stainless steels frequently used as expedients to overcome this problem of contamination. Under many circumstances the assumption is correct that these elements are sufficiently tightly bound in the matrix of the structural material to present no hazard but this situation does not necessarily apply under humid conditions where food material or excreta can remain in contact with the plastic or metal, initiate attack thereon and act subsequently as a source of contamination. The solubility of metal components of commonly used plastics is normally low, but appreciable quantities of metal may be brought into solution if the plastic remains in contact with alkaline solutions such as urine from which free ammonia is being generated. Thus, ammoniacal solutions have become heavily contaminated with copper after a brief period of contact with clear polyvinylchloride tubing. The nature of metallic inclusions may differ in products having the same designation but produced by different manufacturers. Accordingly, when working with elements for which the quantitative requirement is small such as 
selenium, cobalt and chromium, care has to be taken over the selection of structural materials and the choice should be based upon at least a semi-quantitative assessment of trace element content.

Balance experiments for the determination of trace element requirements and availability

There are few satisfactory examples of determination of trace element requirements derived from input/output balance trials. In part, this situation stems from the problems of environmental contamination just described. Additional complications arise in many availability studies because of the very high proportion of the element which may be excreted via the faeces as compared with that in the urine. This applies particularly with the elements copper, zinc, manganese, $\mathrm{Co}$ and $\mathrm{Cr}$ where urinary output may account for only $1-2 \%$ of the total excreted. The difficulties caused by such an unequal partition between faecal and urinary excretion are best illustrated by reference to the example quoted for $\mathrm{Cu}$ balance data in Fig. I which illustrates the effect that relatively minor errors in the determination of faecal $\mathrm{Cu}$ content have upon decisions as to whether an animal is at zero, negative or positive $\mathrm{Cu}$ balance. This figure illustrates a typical situation of a sheep at zero $\mathrm{Cu}$ balance consuming I $\mathrm{kg}$ dry matter per $\mathrm{d}$ in a diet providing $10 \mu \mathrm{g} \mathrm{Cu} / \mathrm{g}$. It is further assumed that the daily faecal output of dry matter is $400 \mathrm{~g}$ and, with $98 \%$ of the ingested $\mathrm{Cu}$ appearing in the faeces, the faecal $\mathrm{Cu}$ concentration would be $24.5 \mu \mathrm{g} / \mathrm{g}$. Most analytical procedures for $\mathrm{Cu}$ determination require that between I and Io $\mu \mathrm{g}$ Cu shall be present; accordingly, it is assumed that I $\mathrm{g}$ of faeces is sampled, digested and subsequently diluted threefold before analysis. The content of $\mathrm{Cu}$ in the faecal subsample ultimately analyzed would thus be $8.2 \mu \mathrm{g}$, as indicated in Fig. 1 . Consider now the effect of a minor error of $\pm 0 \cdot 1 \mu \mathrm{g}$ in the final determination of faecal $\mathrm{Cu}$. When multiplied by the appropriate dilution factors and converted to an expression of total faecal output, such an error, which excludes further errors due to subsampling or environmental contamination, produces an effect on the final $\mathrm{Cu}$ balance which is similar in magnitude to the total daily output of $\mathrm{Cu}$ in the urine.

This example has been described in detail because it illustrates some of the practical problems involved in the determination of apparent availability and trace element balance by such techniques. Similar technical problems are associated with attempts to determine endogenous excretion of some of the trace metals into the gastro-intestinal tract using isotopic techniques. These techniques largely depend upon the establishment of a uniform specific activity between the many forms in which the element may exist in plasma or in urine and the assumption that the specific activity of the metal in these fluids is identical to that in intestinal secretions. Though such assumptions appear to be valid in studies with the alkali metals and to a lesser extent with the alkaline earths, the use of this technique with elements which have a high affinity for specific tissue binding sites or for components of tissue fluids which may differ in turnover rate gives less satisfactory results. Smith, Field \& Suttle (1968) have described such difficulties during attempts 
to determine the endogenous excretion of ${ }^{64} \mathrm{Cu}$ into the gastro-intestinal tract of sheep given low and high molybdenum diets. Among the problems encountered were nonuniform specific activity relationships between different components of blood plasma and between treatment differences in the specific activity of urinary $\mathrm{Cu}$. Once a clearer picture of dynamic relationships between administered radioisotopes and stable trace elements in tissue fluids and endogenous secretions can be obtained, the isotopic approach will have much to commend it. Until such time, this technique

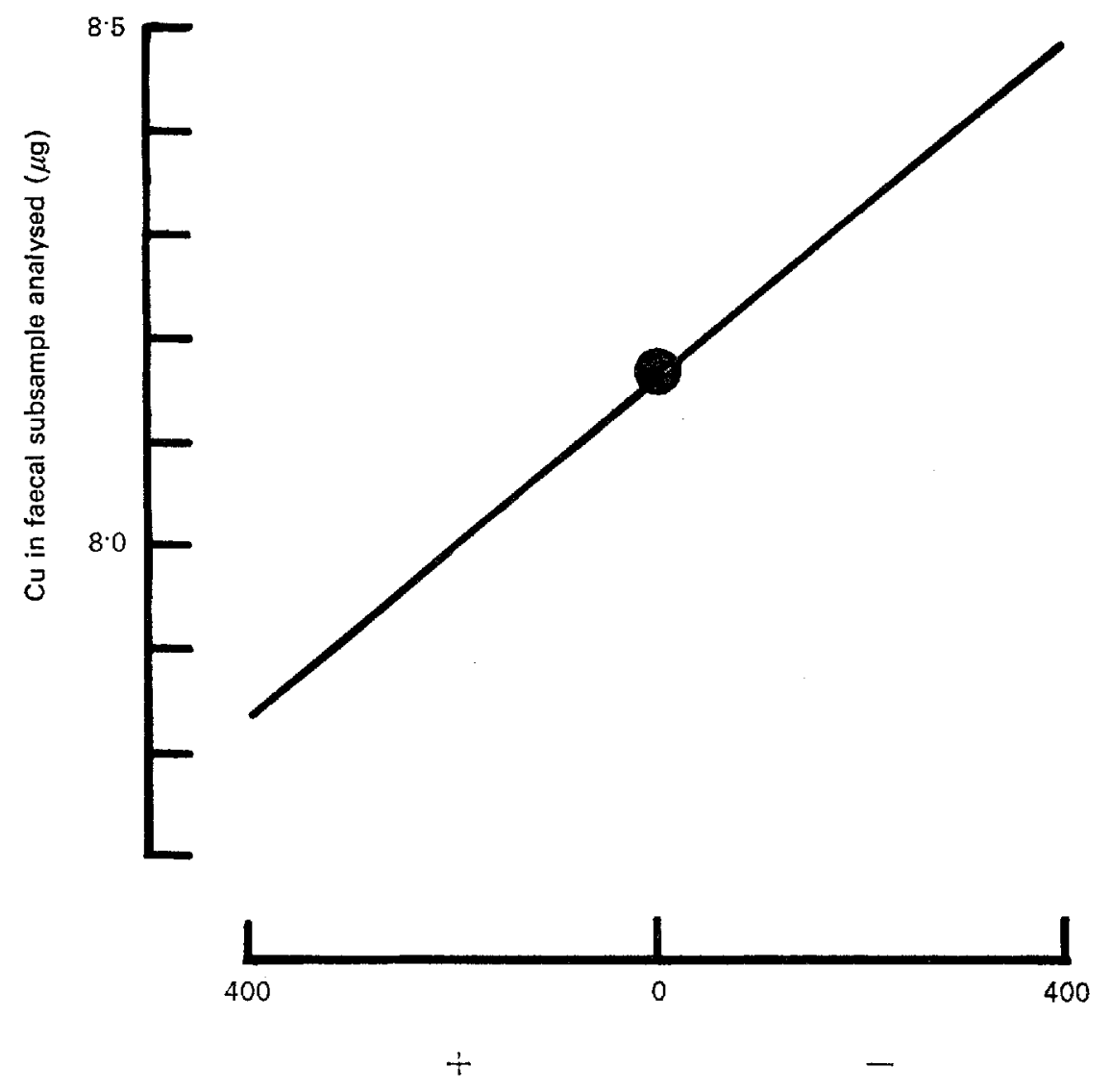

Cu balance $(\mu \mathrm{g} / \mathrm{d})$

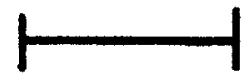

urinary Cu on same scale

Fig. I. The influence of final analytical errors in faecal copper determination upon conclusions regarding $\mathrm{Cu}$ balance, their effect in relation to the daily output of urinary $\mathrm{Cu}$ and to the use of balance techniques for the determination of apparent availability. Errors arising during analysis of food and urine are not included. 
provides only a semi-quantitative assessment of the situation and may in some instances be worthless if the isotope is used solely as a 'marker' for the stable element as an expedient to circumvent problems of environmental contamination.

The existence of a zero or even a positive balance may not always be an indication that the requirement for a particular element has been met by dietary intake. For example, the adverse effects of calcium upon $\mathrm{Zn}$ requirement are, paradoxically, accompanied by an increase in $\mathrm{Zn}$ retention (Kirchgessner, Munz \& Oelschläger, I960).

\section{Dose/response relationships in the determination of trace element requirements}

The greatest progress towards our knowledge of trace element requirements in animals has so far been achieved through studies of dose/response relationships under both experimental and practical conditions. The extent to which this procedure meets our demands for information depends initially upon a clear definition of the nature of the response under study. Studies based solely upon the relationships of trace element intake to early growth ignore the possibility that the requirement may change as growth slows and change yet again during the reproductive phase. Even when studies relating intake to physiological performance are made at different stages of growth, decisions as to 'margins' of safety in the formulation of practical diets remain guesswork unless there is simultaneous study of the effects of different intakes upon tissue reserves and of possible toxic effects.

A very comprehensive investigation providing most of these items of information and thus presenting an excellent assessment of requirements for a trace element is the recently published work of the late H. R. Marston on Co (Marston, 1970). The effects of Co on growth rate of sheep were assessed at eight different levels of intake and these observations were supported by assessing the effects of Co intake upon both serum and liver concentrations of cobalamin and by studies of the effects of Co repletion and depletion upon liver cobalamin stores. Care in the selection of supplementary Co treatments permitted an accurate assessment of intake/growth response relationships, and the experiments illustrated that the requirement for growth is less than that for maximum saturation of liver cobalamin reserves and the establishment of stable cobalamin concentrations in serum. 'This work thus made possible an assessment of maintenance requirements and also of the Co intake needed to maintain a satisfactory safety margin of concentrations of the physiologically active form of this element in tissue depots. Such a detailed investigation is of value both in the establishment of requirements and in the provision of data on tissue composition which could be of use in the clinical assessment of Co status.

Marston's work provides one example of quantitative differences in requirement to meet different functions. Other examples are the work of Ott, Smith, Stob, Parker, Harrington \& Beeson (1965) and Mills, Dalgarno, Williams \& Quarterman ( 1967 ) illustrating that the $Z n$ requirement of ruminants for optimum growth rate is substantially less than for the establishment of normal serum or plasma $\mathrm{Zn}$ con- 
centrations. Detailed studies of relationships between trace element intake and function repeatedly illustrate that it is possible to define requirement both in terms of gross physiological performance and in terms of intakes needed to establish 'normal' or 'saturated' concentrations of tissue stores of the element under investigation. The primary functional roles of both Co and iodine are understood, as is the nature of physiologically available tissue stores of these elements. The task of determining the intakes of these elements needed to promote satisfactory accumulation of available reserves in tissues is relatively straightforward. This is not so with most of the other trace elements where there are doubts about the nature of primary functional roles and about the metabolic availability of tissue depots which accumulate at high levels of intake; in these situations, the assessment of 'margins of safety' becomes largely guesswork.

An incomplete appreciation of the metabolic roles of many of the trace elements means that we can rarely offer an explanation for observed differences in requirement to meet different functions. This situation is frequently encountered in comparative studies of requirements for growth and reproduction. Work with pigs and laboratory animals indicates that poor conception rate, foetal death and resorption and, in some instances, foetal abnormalities, are consequences of suboptimal trace element supply and that these defects often arise without any evidence of other clinical abnormalities in the dam (Plumlee, Thrasher, Beeson, Andrews \& Parker, 1956; Swenerton \& Hurley, 1968; Dutt \& Mills, 1960). The fact that there have been comparatively few systematic and definitive studies of trace element requirements for reproduction makes it impossible to assess the extent to which reproductive performance may be governed by trace element supply under practical conditions. Experimental work in this field is difficult and, with large animals of practical agricultural importance, is time-consuming and expensive to undertake. In consequence, past progress has been based largely upon prophylactic field trials carried out under conditions with limited possibilities of experimental control and often with a small number of animals. It is obvious that, unless facilities are developed for systematic investigation of this topic under conditions which permit closer experimental control and which are backed by adequate financial resources, our present uncertainties as to trace element requirements for reproduction are going to remain.

\section{Dietary factors influencing trace element requirements}

It is beyond the scope of this review to present a comprehensive discussion of those components of diets which have an adverse effect upon trace element utilization and thus influence trace element requirement. Table 2 gives examples of such situations. It must be emphasized that in none of these instances is it yet possible to present a quantitative expression of relationships between the dietary concentration of the antagonist and its effects upon requirement.

A consequence of this situation is that a considerable amount of work must be done if we are to expect precision in statements of requirement for use under practical 
conditions. Whether the attempts to obtain such precision are justifiable is debatable. If, in order to obtain a reliable assessment of the adequacy of the trace element component of a diet, it is necessary to determine both the concentrations of these elements and those of factors known to be of practical importance in modifying requirement, the analytical task becomes formidable. The alternative is to accept that statements of trace element requirement will remain approximations, to accept that there is only a qualitative understanding of the nature of possible interacting factors and to appreciate that by using certain dietary ingredients there is a probability that requirement may be substantially modified and margins of safety

Table 2. A summary of dietary components which, when present at high concentrations, are known to modify trace element utilization or apparent requirement*

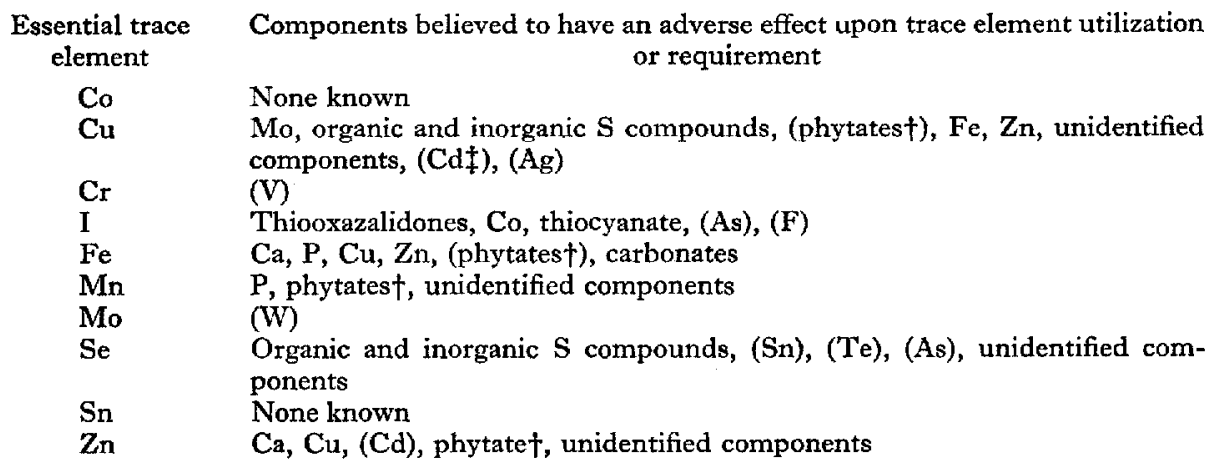

*Derived from: Hill \& Matrone (1970); Mills (1970); Underwood (1962, 1966).

†Principally applicable to non-ruminant species but may also apply to ruminants before rumen function fully developed.

IComponents in parentheses refer to experimental studies only; not yet established under practical circumstances.

may have to be adjusted. The success of this alternative places a greater premium upon rapid recognition of marginal deficiency states and it is in this sphere that there is the greatest demand for improvement and progress. By exploiting our knowledge of the primary metabolic roles of Co and iron, rapid methods have been developed which can provide a reliable assessment of suboptimal status. Although some progress has been made towards the same objective with the other essential trace elements, a substantial amount of work remains to be done before any of these techniques can be applied under practical conditions.

The greatest demands for accuracy in statements of trace element requirement and for an understanding of the factors which may modify requirement exist in studies of experimental nutrition and in the formulation of basal diets to be used in bioassay procedures for the determination of other possible limiting nutrients. To emphasize this point, the Association of Official Agricultural Chemists (1965) method for the determination of protein efficiency ratios with rats relies upon the use of a mineral salt mix (US Pharmacopaeia, XVII) which at the maximum 
level of inclusion will only provide $6 \mathrm{ppm} \mathrm{Zn}$; under the most favourable circumstances this will only meet about $50 \%$ of the requirements of the rat for growth. In this assay the remainder of the $\mathrm{Zn}$ requirement must be met either by chance contamination from components of the basal diet, from the test protein or from the environment. Many protein sources under test may well meet this deficit but protein sources such as soya-bean meal rich in the $\mathrm{Zn}$-binding factor, phytic acid, may not provide sufficient available $\mathrm{Zn}$ and thus biological response becomes conditioned partly by the amino acid composition of the test protein and partly by available $\mathrm{Zn}$ supply. The hazards of this situation were first illustrated by Oberleas and Prasad (1970) and are also being encountered in other work with chicks. The recent growth in our information on trace element requirements also throws into doubt some earlier experimental studies on vitamin deficiencies in which $\mathrm{Zn}$ was probably an additional limiting nutrient as a consequence of the use of inadequate mineral supplements in experiments with synthetic diets.

\section{Conclusion}

People tend to hold passionate views upon the importance of the trace elements in nutrition. Some attribute every disorder not clearly associated with a pathogen to a deficiency or an excess of a trace element: others dismiss the trace elements as being irrelevant under practical conditions, assuming a ubiquitous supply from the environment. These situations arise because requirements are so inadequately defined. We have presented some of the reasons why progress in the determination of trace element requirements is, of necessity, slow. We have also attempted to assess the practical benefit which might accrue from more accurate statements and have emphasized that the application of this knowledge in practice might be limited by the magnitude of analytical problems. It is suggested that many of these difficulties can be overcome through a greater understanding of the circumstances which may modify requirements and through the more effective recognition of impaired physiological performance due to trace element deficiency and excess. All these fields demand considerable research effort if progress is to be made so that if this review only illustrates the nature of the tasks that lie ahead it will have served its purpose.

\section{REFERENCES}

Agricultural Research Council (1963). The Nutrient Requirement of Farm Livestock. No. ז. Poultry. London: Agricultural Research Council.

Agricultural Research Council (1965). The Nutrient Requirements of Farm Livestock. No. 2. Ruminants. Landon: Agricultural Research Council.

Agricultural Research Council (1967). The Nutrient Requirements of Farm Livestock. No. 3. Pigs. London: Agricultural Research Council.

Association of Official Agricultural Chemists (1965). Official Methods of Analysis roth ed. p. 785 . Washington DC: Association of Official Agricultural Chemists.

British Standards Institution (1950). B.S. 971 : 1950. London: British Standards Institution.

British Standards Institution (I955). B.S. 970: 1955. London: British Standards Institution.

British Standards Institution (1963). B.S. 1490: 1963. London: British Standards Institution.

Dutt, B. \& Mills, C. F. (1960). F. comp. Path. Ther. 70, 120.

Hill, C. H. \& Matrone, G. (1970). Fedn Proc. Fedn Am. Socs exp. Biol. 29, 1474. 
Kirchgessner, M., Munz, W. \& Oelschläger, W. (1960). Arch. Tieremähr. xo, x.

Marston, H. R. (1970). Br. F. Nutr. 24, 6r5.

Mills, C. F. (editor) (1970). Trace Element Metabolism in Animals. Edinburgh: Livingstone.

Mills, C. F., Dalgarno, A. C., Williams, R. B. \& Quarterman, J. (I967). Br. F. Nutr, 2r, 75 r.

National Research Council (1960). Publs natn. Res. Coun., Wash. no. 827.

National Research Council (1964). Publs natn. Res, Coun., Wash. no. I I92.

National Research Council (1966). Publs natn. Res. Coun., Wash. no. 1349.

National Research Council (1968a). Publs natn, Res. Coun., Wash. no. I694.

National Research Council (1968b). Publs natn. Res. Coun., Wash. no. I693.

National Research Council (1970). Publs natn. Res. Coun., Wash. no. I $37,4^{\text {th }}$ ed.

Oberleas, D. \& Prasad, A. S. (1970). In Trace Element Metabolism in Animals p. I70 [C. F. Mills, editor]. Edinburgh: Livingstone.

Ott, E. A., Smith, W. H., Stob, M., Parker, H. E., Harrington, R. B. \& Beeson, W. M. (1965). Y. Nutr. 87,459 .

Plumlee, M. P., Thrasher, D. M., Beeson, W. M., Andrews, F. N. \& Parker, H. E. (1956). F. Anim. Sci. I5, 352 .

Scott, R. O. (1970). In Trace Element Metabolism in Animals p. 497. [C. F. Mills, editor]. Edinburgh: Livingstone.

Smith, B. S. W., Field, A. C. \& Suttle, N. F. (1968). F. comp. Path. Ther. 78, 449.

Swenerton, H. \& Hurley, L. S., (1968). F. Nutr. 95, 8.

Underwood, E. J. (1962). Trace elements in Htman and Animal Nutrition and ed. New York and London: Academic Press.

Underwood, E. J. (1966). The Mineral Nutrition of Livestock. Farnham Royal: Commonwealth Agricultural Bureaux.

\section{Genetic variation in mineral metabolism of ruminants}

By Gerald Wiener, Agricultural Research Council, Animal Breeding Research Organisation, Edinburgh EH9 $37 Q$ and A. C. FIELD, Moredun Research Institute, Edinburgh $\mathrm{EH}_{\mathbf{1}} 77^{\mathscr{f} H}$

The occurrence of disorders of mineral metabolism in cattle and sheep, for example hypocalcaemia, hypomagnesaemia or swayback, suggests that some individuals are unable to meet their mineral requirements. The question arises whether such differences among individuals are inherited and can be affected by a breeding policy.

The incidences of most of the metabolic disorders are low and sporadic, even though costly. Generally, under these circumstances little progress can be expected in reducing the incidence of these metabolic disorders in future generations by removing, or allowing nature to remove, only the clinically affected animals from the breeding population. Even such little change as might be expected from natural selection is counteracted by normal husbandry and veterinary practices which preserve deficient individuals by rescuing them from the consequences of disorder or by preventing its manifestation (an example relating to swayback is discussed by Wiener (I97I)).

Genetic progress in reducing metabolic disorders is most likely to be made if the underlying biochemical variation is understood, is measurable in apparently healthy animals and is inherited. More urgency is given to finding answers to the appropriate questions if the disorders are expected to increase in frequency as higher 